\title{
Incorporating cooling and ventilation effects into a single IEQ indicator
}

\author{
Matjaž Prek ${ }^{1, *}$, Gorazd Krese $^{2}$, and Žiga Lampret ${ }^{1}$ \\ ${ }^{1}$ University of Ljubljana, Faculty of Mechanical Engineering, Ljubljana SI-1000, Slovenia \\ ${ }^{2}$ Korona inženiring d.d., Ljubljana SI-1000, Slovenia
}

\begin{abstract}
The influence of dissimilar cooling and ventilation system combinations on indoor environmental quality (IEQ) has been studied. A comparison of chilled ceiling cooling in combination with displacement ventilation, cooling with fan coil unit, and cooling with flat wall displacement inlets was performed. All observed variations were evaluated based on whole-body and local thermal comfort criteria as well as with regard to ventilation effectiveness. The analysis was made based on results of numerical simulations carried out in two steps. First, DesignBuilder was applied to model the buildings' thermal performance and to evaluate its interaction with the environment. The latter included the calculation of heat gains as well as the heat loss on the boundary surfaces of the observed air-conditioned room. In the second step, ANSYS Fluent was used to simulate the response of indoor environment by utilizing the simulation results obtained in the first step, in order to evaluate the interaction between building and human. Afterwards, the observed thermal comfort and ventilation criteria were merged into a novel indoor environment indicator, which enables to describe the indoor environment quality with a single value. Among the analysed systems, the ceiling cooling system in combination with displacement ventilation was found to be the most suitable as it offers a high level of thermal comfort with adequate ventilation efficiency. Fan coil cooling was the least favourable option in terms of thermal comfort, while flat wall displacement inlets exhibited the lowest ventilation effectiveness. The performed investigation demonstrated the necessity to assess indoor environment with regard to IEQ in addition to energy consumption.
\end{abstract}

\section{Introduction}

Energy consumption in buildings has been steadily rising in recent years. In EU more than $40 \%$ of the primary energy consumption is due to the energy use in buildings [1]. In developed countries people spend between $80 \%$ and $90 \%$ of their time in indoor environment [2]. It is therefore very important to consider the impact of indoor environment on the occupants' health and thermal comfort sensation In particular, cooling and ventilation will have an increasingly important role in achieving satisfactory indoor environment conditions in the future due to global warming.

Cooling systems impact is typically evaluated with thermal comfort and local discomfort indices whereas ventilation is evaluated with air change efficiency (ACE) or contaminant removal effectiveness (CRE) [3]. When designing the indoor environment, joint assessment of thermal comfort and air quality in necessary in order to ensure an adequate and healthy indoor environment for building users.

\section{Literature review}

\subsection{Impact of cooling and ventilation}

While many researchers have studied the impact of different combinations of cooling and ventilation systems from the point of view of thermal comfort or ventilation effectiveness, there are few studies that tackle both these aspects simultaneously.

Tomasi et al. [4] carried out an experimental study on the impact of the inlet and outlet openings and ventilation rates on the thermal comfort and ventilation effectiveness when using floor cooling system. Both the $\mathrm{ACE}$ and CRE indices were determined to assess the ventilation effectiveness. Air inlets location had impact on ventilation effectiveness not on the thermal comfort while higher ventilation rates had positive effect on the ventilation effectiveness.

Schellen et al. [5] experimentally investigated various cooling systems (combinations of passive or active cooling systems with mixing and displacement ventilations) impact on the thermal comfort (PMV) [6] as well as local thermal comfort indices. Measured index

\footnotetext{
* Corresponding author:
} 
values were compared with actual physiological response of people. Even though all the cases were designed for $\mathrm{PMV} \approx 0$, subjective data indicated significant discrepancies between combinations. Under isothermal conditions floor cooling system combined with displacement ventilation proved as the most favourable, while the least favourable was the air injection system. Combined local factors played an important role in comfort assessment. Non-uniform environments were assessed comparable or even more comfortable compared to uniform environments.

Gan [7] evaluated thermal comfort and ventilation effectiveness of a mechanically ventilated room with computational fluid dynamics (CFD), for different heating and cooling operations. The most effective air distribution system for heating differed from that for cooling. The air distribution system with upward displacement ventilation had the best performance in terms of indoor air quality and energy use, but fared worse in terms of local thermal discomfort.

\subsection{Numerical simulations}

Besides experimental measurements, CFD simulations are one of the most common approaches for evaluating indoor environments. Accurate prediction of air velocity, temperature and other thermal conditions in a room is crucial when designing high-quality air conditioning and ventilation systems. The accuracy of CFD simulations depends on the appropriate setting of boundary conditions and numerical simulation parameters. A literature review was conducted to establish the appropriate settings (turbulent models, calculation schemes for velocity and pressure fields, heat pressure models) to use in the presented study. On the other hand, the radiation model selection and velocity and pressure fields' calculation was done according to the guidelines of CFD software vendors. [8]

Chen [9] evaluated five different $\mathrm{k}-\varepsilon$ turbulent models for their performance in predicting different indoor environment situations, whereby he used experimental data from literature for the validation. The RNG k- $\varepsilon$ model performed slightly better than the standard $\mathrm{k}-\varepsilon$ model and was recommended for simulations with indoor air flow. Rouaud et al. [10] found that the standard $\mathrm{k}-\varepsilon$ model and the RNG k- $\varepsilon$ model satisfactory predicted the main flow characterises as the numerical results agreed with experimental measurements. However, the RNG $\mathrm{k}-\varepsilon$ model better predicted swirl and complex trajectories and was subsequently proposed as more suitable to calculate the airflow in clean rooms.

Gadgil et al. [11] used CFD predictions of indoor pollutant mixing time in an unventilated, mechanically mixed isothermal closed room and concluded that CFD predictions were in good agreement with experimental measurements. Srebrič et al. [12] evaluated different boundary conditions settings on the simulation accuracy for contaminant dispersion, heat transfer and airflow simulations around human occupants in indoor environments. Numerical simulations were in agreement with environmental chambers experiments.

\section{Theoretical background}

\subsection{Thermal comfort}

Thermal comfort was evaluated by simulating the indoor environment parameters, presented in Table 1.

Table 1. Simulated parameters.

\begin{tabular}{|c|c|c|}
\hline Symbol & Parameter & Unit \\
\hline $\mathrm{t}_{\mathrm{a}}$ & air temperature & ${ }^{\circ} \mathrm{C}$ \\
\hline $\mathrm{t}_{\mathrm{mr}}$ & mean radiant temperature & ${ }^{\circ} \mathrm{C}$ \\
\hline $\mathrm{Var}_{\mathrm{R}}$ & relative air flow velocity & $\mathrm{m} / \mathrm{s}$ \\
\hline $\mathrm{RH}$ & relative humidity & $\%$ \\
\hline $\mathrm{t}_{\mathrm{o}}$ & operative temperature & ${ }^{\circ} \mathrm{C}$ \\
\hline
\end{tabular}

Thermal environment was assessed in accordance with the established standards [13,14], from the point of view of whole body thermal comfort (PMV and PPD) and local discomfort. The indices calculated for the thermal environment analysis are listed in Table 2.

Table 2. Thermal indices.

\begin{tabular}{|c|c|c|}
\hline Symbol & Indices & Unit \\
\hline \multicolumn{3}{|c|}{ Whole body thermal comfort } \\
\hline PMV & predicted mean vote & {$[/]$} \\
\hline $\mathrm{PPD}$ & predicted percentage of dissatisfied & {$[/]$} \\
\hline $\mathrm{V}_{\mathrm{ar}}$ & relative air flow velocity & $\mathrm{m} / \mathrm{s}$ \\
\hline \multicolumn{3}{|c|}{ Local discomfort } \\
\hline $\mathrm{DR}$ & draught rate & $\%$ \\
\hline $\mathrm{PD}_{\Delta \mathrm{t}, \mathrm{v}}$ & vertical temperature difference & $\%$ \\
\hline $\mathrm{PD}_{\Delta \mathrm{t}, \mathrm{pr}}$ & radiant temperature asymmetry & $\%$ \\
\hline $\mathrm{PD}_{\mathrm{t}, \mathrm{f}}$ & floor temperature & $\%$ \\
\hline
\end{tabular}

\subsection{Ventilation effectiveness}

Among the air change efficiency and contaminant removal effectiveness methods for assessing the ventilation effectiveness, the latter was used in this study. The CRE method describes the ability of a system to remove air-borne contaminants. It is defined as the ratio between mean concentration of contaminants in the exhaust air and the mean concentration in the room, when the steady state was reached. CRE can take any positive value and depends not only on the airflow pattern within the room but also on the position of the contaminant source relative to the air outlet.

\subsection{Combining thermal comfort and ventilation effectiveness parameters}

Contrary to other studies, where thermal comfort and ventilation were evaluated separately, we intended to evaluate the indoor environment quality with a combined indicator $I_{I E Q}$. The joint assessment of both parameters was made, in the same manner as for thermal comfort 
assessment, by introducing categories of indoor environment [15]. The following function for calculating the combined effect was developed:

$$
I_{I E Q}=W_{I E Q} \cdot X+\left(1-W_{I E Q}\right) \cdot Y
$$

Different parameters in Eq. 1 represent:

- $X$ - numerical value of the thermal environment category $(\mathrm{A}=1, \mathrm{~B}=2, \mathrm{C}=3)$

- $Y$ - numerical value of the ventilation effectiveness; categories' numerical values were unified with thermal comfort categories, whereas the width of the ventilation efficiency intervals for each category was determined according to the indoor environment experiments described in [3]; categories and intervals are as follows:

$$
\begin{array}{ll}
\circ & Y=1 ; 1.0 \leq C R E<\infty \\
\circ & Y=2 ; 0.5 \leq C R E<1.0 \\
\circ & Y=3 ; 0 \leq C R E<0.5
\end{array}
$$

- $W_{I E Q}$ - indoor environment quality weight; it determines importance of individual indoor environment parameter, based on its value from the interval $[0,1]$. It's value is dependent on the space use, i.e. for residential and office spaces, where harmful substances are not expected to pose major health risk, a suitable weight value is estimated between 0.5 and 0.7

The indoor environment quality indicator $I_{I E Q}$ can therefore be valued on the interval $[1,3]$. Similar to the thermal comfort environment categories, the interval for the indoor environment indicator was evenly distributed between different indoor environment categories:

- A - good quality of the indoor environment; $1.0 \leq I_{I E Q} \leq 1.65$

- B - medium quality of the indoor environment; $1.65<I_{\text {IEQ }} \leq 2.3$

- $\mathrm{C}-$ low quality of the indoor environment; $2.3<I_{I E Q} \leq 3.0$

\section{Methodology}

In the first step of numerical simulations heat gains (building and individual space) as well as the heat flows of the boundary surfaces in the room were calculated with the simulation software DesignBuilder. Results were used in the second step for simulating the indoor environment with the CFS software ANSYS Fluent.

\subsection{DesignBuilder}

\subsubsection{Model description and building envelope}

Heat gain calculations were made for a two storey building (whole building and single office calculation) with an identical room configuration (three identical offices and a corridor) on the ground and first floor. Dimensions for each single person office were $\mathrm{L} x \mathrm{~W} \times$ $\mathrm{H}=3.5 \mathrm{~m} \times 3 \mathrm{~m} \times 2.5 \mathrm{~m}\left(\mathrm{~A}=10.5 \mathrm{~m}^{2} ; \mathrm{V}=26.25 \mathrm{~m}^{3}\right)$. The building model is shown in Fig. 1.
Boundary conditions that determine the heat gains of each office, as well as the conditions for determining the thermal comfort indices, are listed in Table 3.

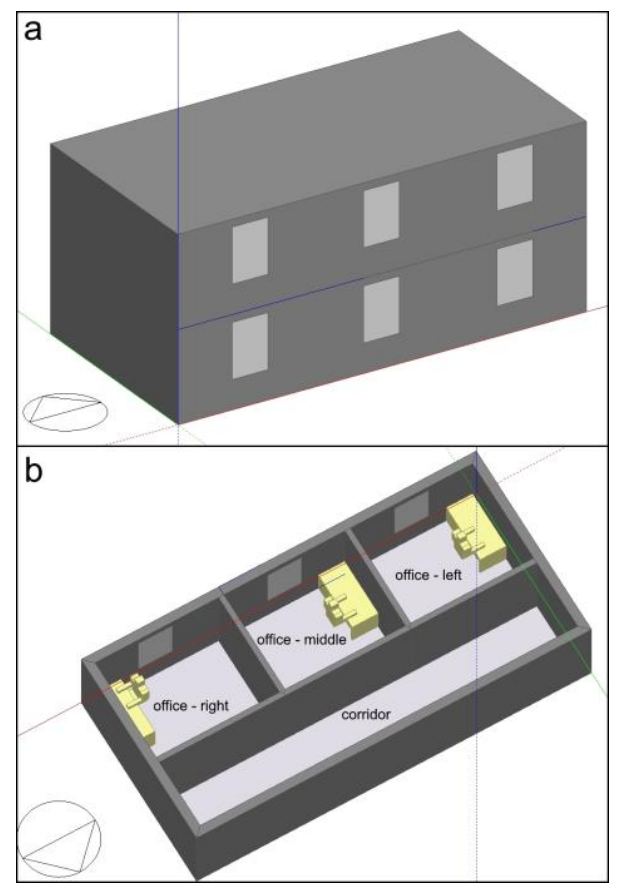

Fig. 1. (a) building model; (b) ground floor.

The values associated with system operation, the supply of fresh air and the lighting of the rooms are determined in accordance with established standards and policies $[14,16,17]$. Designed air temperature at the time of occupancy was $26^{\circ} \mathrm{C}$. Model location, important for evaluating solar radiation, is Ljubljana, Slovenia, the orientation of the offices is towards the south.

\begin{tabular}{|c|c|c|c|}
\hline \multicolumn{4}{|c|}{ Opaque surfaces } \\
\hline \multicolumn{2}{|c|}{ Building element } & \multicolumn{2}{|c|}{$\begin{array}{l}\mathbf{U}-\text { value } \\
{\left[\mathrm{W} / \mathbf{m}^{2} \mathbf{K}\right]}\end{array}$} \\
\hline \multicolumn{2}{|c|}{ outer wall } & \multicolumn{2}{|c|}{0.28} \\
\hline \multicolumn{2}{|c|}{ inside wall } & \multicolumn{2}{|c|}{1.54} \\
\hline \multicolumn{2}{|c|}{ ceiling between heated spaces } & \multicolumn{2}{|c|}{0.76} \\
\hline \multicolumn{2}{|c|}{ ground } & \multicolumn{2}{|c|}{0.25} \\
\hline \multicolumn{2}{|c|}{ roof } & \multicolumn{2}{|c|}{0.16} \\
\hline \multicolumn{4}{|c|}{ Transparent surfaces } \\
\hline Building element & $\begin{array}{l}U-\text { value } \\
{\left[W / m^{2} K\right]}\end{array}$ & $g$ l/ & $\tau_{D 65}$ \\
\hline Window & 0.78 & 0.47 & 0.66 \\
\hline
\end{tabular}

Table 3. Boundary conditions.

\begin{tabular}{|c|c|}
\hline Parameter & Value \\
\hline Room occupancy & $7: 00-17: 00$ \\
\hline Metabolic rate & $1,2 \mathrm{met}$ \\
\hline Clothing [16] & $0,6 \mathrm{clo}$ \\
\hline Fresh air supply rate & $30 \mathrm{~m}^{3} / \mathrm{h}$ \\
\hline Illuminance [17] & $500 \mathrm{lux}$ \\
\hline
\end{tabular}

Table 4. Building elements. 
Building envelope elements were modelled in compliance with the Energy Performance of Buildings Directive [18]. Due to south facing windows orientation, external blinds were chosen as an additional protection against direct sun radiation. Actual properties of the building elements (opaque and transparent surfaces) are shown in Table 4.

\subsubsection{Cooling and ventilation systems}

Three cooling and ventilation systems were compared:

- chilled ceiling cooling in combination with displacement ventilation (a)

- fan coil unit (b)

- cooling with flat wall displacement inlets (c).

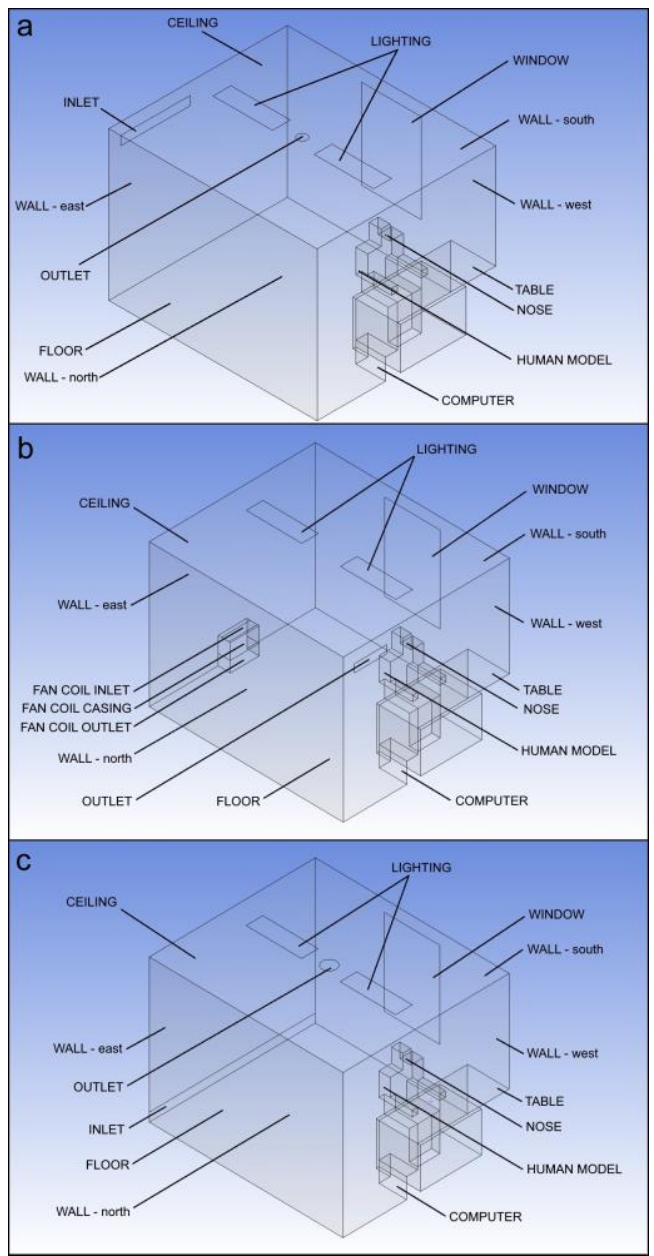

Fig. 2. Compared AC systems: (a) chilled ceiling cooling; (b) fan coil unit; (c) cooling with flat wall displacement inlets.

Chilled ceiling cooling was chosen as a novel cooling system, which utilizes radiative cooling with minimum necessary fresh air intake. Fan coil unit is a wellestablished simple and flexible cooling system, where heat is exchanged via convection between the coils and the moving air. Cooling with flat wall displacement inlets enables air cooling with low inlet air flow speeds. Fig. 2 shows the simulated combinations, as they were modelled in the DesignBuilder software environment.

\subsection{ANSYS Fluent}

ANSYS Fluent software package was used to simulate the interaction between building and human for three different AC system combinations. Individual steps, relevant to the simulation results, are presented in the subsequent subchapters.

\subsubsection{D modelling and meshing}

3D modelling of the calculation scheme was followed by the generation of a meshing, with the embedded ANSYS Fluent meshing module. Office geometry, taken from the DesignBuilder model, is a simplified portrait of the real office with the simplification of the geometry for mesh generation. In the process of making the mesh, we focused on the appropriate choice of the size of the finite volumes or cells and the thickening of the mesh in places where we expected larger velocity and temperature gradients. The mesh was thickened with the functions Inflation and Face sizing. The inflation function creates a transition between smaller and larger cells at a certain surface. This thickening was used in the case of chilled ceiling cooling where the grid was thickened in layers near the ceiling and the floor. With Face Sizing, we define the size of the elements on the surface of the mesh. This function was used for thickening the mesh on a small surface representing a human nose and on the inlet/outlet surfaces of the fan coil unit.

\subsubsection{Turbulence and radiative models}

Despite expected low air velocities in the room, airflow was regarded as turbulent due to local airflow fluctuations. Selected $\mathrm{k}-\varepsilon-\mathrm{RNG}$ turbulent model was in accordance with literature recommendations [10].

For radiative heat transfer the Surface to Surface model was selected, which is especially important in the case of chilled ceiling cooling. This model is suitable for calculating radiation in closed computing domains with a non-radiative medium and is based on the calculation of angular factors between surfaces [8].

\subsubsection{Boundary and starting conditions}

For the calculations it was assumed that all surfaces had an emissivity of 0.9 , water evaporation on the skin surface was neglected, and a homogeneous velocity profile was assumed at inlet openings. The turbulence intensity and viscosity ratio parameters were selected in accordance with [10].

The following boundary conditions were assumed for all three cooling configurations: heat flows from the boundary surface of the human model, lighting, tables, nose, windows, computer, peripheral walls and floor. The air velocity through the nasal aperture was determined on the basis of the fact that a person at rest exhales approximately $6 \mathrm{l} / \mathrm{min}$ of air. Exhale direction 
$70^{\circ}$ toward the ground (relative to the horizontal plane) with constant nasal airflow was assumed. Boundary conditions specific for individual combinations were adjusted accordingly.

In the case of chilled ceiling cooling, an air inlet for Q-WL 125 displacement ventilation with a dimension of $0.15 \times 1.17 \mathrm{~m}$ was selected for the fresh airflow [19]. A circular ceiling outlet RFD-R-160 with a diameter of $0.158 \mathrm{~m}$ was selected for the air outflow [20].

For fan coil unit simulations, a typical convector, which allowed an appropriate flow of $300 \mathrm{~m}^{3} / \mathrm{h}$ at an inlet air temperature of $293 \mathrm{~K}$ (adequate heat output for the calculated cooling load), was selected [21]. The opening of the inlet air has dimensions of $0.13 \mathrm{~m} \mathrm{x} 0.25$ $\mathrm{m}$, and the opening for the circulation air is $0.19 \mathrm{~m} \mathrm{x}$ $0.52 \mathrm{~m}$. A wall rectangular outlet opening FA-VT with a nominal length of $0.6 \mathrm{~m}$ in a single embodiment was selected for the outflow [22].

Flat wall inlets positioned along the entire length of the eastern wall (height $=0.15 \mathrm{~m}$ ) were selected for flat wall displacement inlets [16]. The maximum inlet air velocity $0.2 \mathrm{~m} / \mathrm{s}$ and minimum inlet air temperature $20^{\circ} \mathrm{C}$ were assigned to avoid draught discomfort. A typical airflow outlet was selected from [23] with a diameter of $0.249 \mathrm{~m}$.

For initial conditions, the initial air temperature of $26^{\circ} \mathrm{C}$ was selected since boundary conditions alone do not suffice to determine the surface temperatures

\subsubsection{Post-processing}

For thermal comfort indices (PMV and local discomfort) assessment temperature and velocity fields data were simulated, whereas for the CRE evaluation concentration fields were simulated.
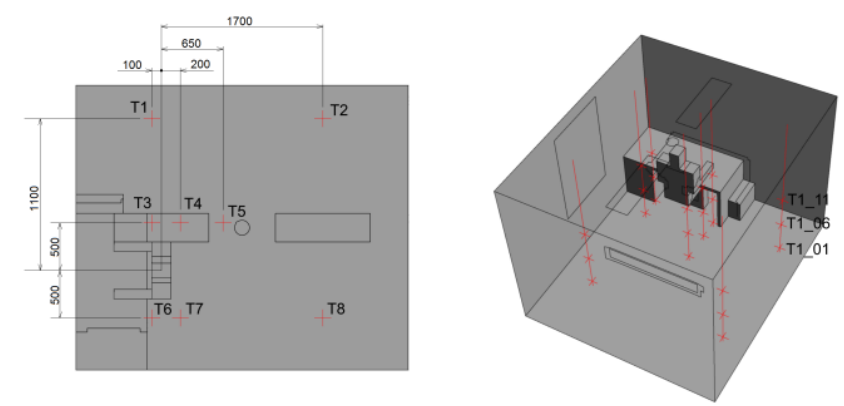

Fig. 3. (a) Post processing calculation.

All parameters were calculated for the simulated room in eight positions at three heights. Different heights are noted with digits $(01-$ height $0.1 \mathrm{~m}, 06-0.6 \mathrm{~m}, 11-$ $1.1 \mathrm{~m})$. The calculation grid is shown in Fig. 3. The distances shown in Fig. 3 are given according to the coordinates of the human body model's centre of mass. Four points are located in the immediate vicinity of the human body model (occupied zone), others are positioned further away from the human model. In this way the whole room was evaluated, with an emphasis given to the vicinity of the human body.

\section{Results}

\subsection{DesignBuilder - heat gains}

Design builder calculation results served for determining the boundary conditions for the ANSYS Fluent simulation. Per calculation results the maximum cooling load of $0.653 \mathrm{~kW}(0.587 \mathrm{~kW}$ without latent heat gains) on the selected day was reached at 15:00.

\subsection{Velocity and temperature field}

Room flow pathlines are seen in Fig.4 (column 1). In the case of chilled ceiling cooling and flat wall inlets, displacement ventilation is established, activated by the heat sources (computer, human) which influence the buoyancy. The fan coil unit pathlines indicate mixing ventilation with the air flow jet, i.e. air flow that exits the fan coil flows into the ceiling and is then diverted toward the floor. There it spreads in all directions and slowly starts to rise toward the ceiling and the outlet opening.

Column 2 in Fig. 4 shows the velocity field in the $\mathrm{XY}$ orthogonal cross-section through the person's centre of mass. Flow velocity information is important, especially from the point of potential draught discomfort.

The temperature field results are illustrated in Fig.4 (column 3). For chilled ceiling cooling the temperature field is very homogenous which results in a thermally comfortable environment. In the case of flat wall displacement inlets, the temperature field is different in comparison to the other two cases. As expected thermal stratification occurs, although it does not yet cause thermal discomfort. In the case of fan coil cooling, noticeable temperature gradients are present in the air supply area, whereas in the other part of the room the temperature field is far less heterogeneous. Chilled ceiling cooling results in an almost vertical temperature profile. In the case of flat wall inlets, the occurrence of stratification can be observed, whereas the temperature profiles for the fan coil unit case indicate that the temperature for this mode also varies in the other two spatial coordinates.

\subsection{Thermal comfort}

Thermal comfort indices were calculated for 24 points in the room ( 8 points, 3 heights). Table 5 shows the physical parameters as well as whole body thermal comfort and local discomfort indices.

Values relating to the occupied zone are noted with the OZ index, values relating to the ankle height are noted with the 0.1 index whereas the average values are denoted with angle brackets. The column "TE cat." notes the thermal environment categories [15] for different indices.

For chilled ceiling cooling, the average air flow velocity is fairly low due to the low air supply rate, as seen in Table 5. Similar observations can be made in the case of flat wall displacement inlets, where an increase of average velocity is seen near the floor. For chilled 
ceiling cooling, the average temperature only slightly deviates from the desired air temperature which is not the case for the flat wall inlets, due to the thermal stratification and lower temperatures in the occupied zone. Ceiling cooling noticeably decreases mean radiant temperature in comparison and subsequently lowers the operative temperature.

Table 5. Simulated thermal comfort indices.

\begin{tabular}{|l|c|c|c|c|c|c|}
\hline \multicolumn{1}{|c|}{ Symbol } & $\begin{array}{c}\text { Ceiling } \\
\text { cooling }\end{array}$ & $\begin{array}{c}\text { TE } \\
\text { cat. }\end{array}$ & $\begin{array}{c}\text { Fan } \\
\text { coil } \\
\text { unit }\end{array}$ & $\begin{array}{c}\text { TE } \\
\text { cat. }\end{array}$ & $\begin{array}{c}\text { Flat } \\
\text { wall } \\
\text { intlet }\end{array}$ & $\begin{array}{c}\text { TE } \\
\text { cat. }\end{array}$ \\
\hline$\langle\mathrm{v}\rangle[\mathrm{m} / \mathrm{s}]$ & 0,05 & - & 0,10 & - & 0,04 & - \\
\hline$\left\langle\mathrm{v}_{0,1}\right\rangle[\mathrm{m} / \mathrm{s}]$ & 0,06 & - & 0,17 & - & 0,14 & - \\
\hline$\left\langle\mathrm{t}_{\mathrm{i}}\right\rangle\left[{ }^{\circ} \mathrm{C}\right]$ & 25,4 & - & 26,4 & - & 23,0 & - \\
\hline$\left\langle\mathrm{t}_{\mathrm{mr}}\right\rangle_{\mathrm{BC}}\left[{ }^{\circ} \mathrm{C}\right]$ & 25,0 & - & 28,8 & - & 25,9 & - \\
\hline$\left\langle\mathrm{t}_{\mathrm{o}}\right\rangle_{\mathrm{BC}}\left[{ }^{\circ} \mathrm{C}\right]$ & 25,1 & - & 27,3 & - & 23,8 & - \\
\hline$\langle\mathrm{PMV}\rangle[/]$ & 0,25 & $\mathrm{~B}$ & 0,71 & $\mathrm{C}$ & $-0,26$ & $\mathrm{~B}$ \\
\hline$\langle\mathrm{PPD}\rangle[\%]$ & 6,1 & $\mathrm{~B}$ & 15,6 & $\mathrm{C}$ & 6,4 & $\mathrm{~B}$ \\
\hline$\left\langle\mathrm{PMV} \mathrm{OZ}_{\mathrm{OZ}}\right\rangle[/]$ & 0,22 & $\mathrm{~B}$ & 0,71 & $\mathrm{C}$ & $-0,25$ & $\mathrm{~B}$ \\
\hline$\left\langle\mathrm{PPD} \mathrm{O}_{\mathrm{OZ}}\right\rangle[/]$ & 6,0 & $\mathrm{~B}$ & 15,7 & $\mathrm{C}$ & 6,3 & $\mathrm{~B}$ \\
\hline $\mathrm{PD}_{\mathrm{t}, \mathrm{f}}[\%]$ & 6,11 & $\mathrm{~A}$ & 10,3 & $\mathrm{~B}$ & 6,1 & $\mathrm{~A}$ \\
\hline$\left\langle\mathrm{DR}{ }_{\mathrm{OZ}}\right\rangle[\%]$ & 1,0 & $\mathrm{~A}$ & 8,3 & $\mathrm{~A}$ & 8,6 & $\mathrm{~A}$ \\
\hline$\left\langle\mathrm{DR}_{\mathrm{OZ}, 01}\right\rangle[\%]$ & 0,2 & $\mathrm{~A}$ & 12,3 & $\mathrm{~A}$ & 10,6 & $\mathrm{~A}$ \\
\hline$\left\langle\mathrm{PD}_{\Delta \mathrm{t}, \mathrm{v}}\right\rangle[\%]$ & 0,4 & $\mathrm{~A}$ & 0,4 & $\mathrm{~A}$ & 1,5 & $\mathrm{~A}$ \\
\hline$\left\langle\mathrm{PD}_{\Delta \mathrm{t}, \mathrm{pr}}\right\rangle[\%]$ & 0,01 & $\mathrm{~A}$ & - & - & - & - \\
\hline
\end{tabular}

According to the PMV and PPD indices ceiling cooling and flat wall openings fare quite similarly with regards to the deviation from the thermal neutrality. Both systems achieve category B, nearly missing category A. In the case of fan coil unit, the simulated PMV values are higher, i.e. the system achieves category C. This is mainly due to the high mean radiant temperature of surrounding surfaces and a warm thermal sensation even at comfortable suitable air temperature.
All the systems achieve the highest categories in relation to the local discomfort indices. Ceiling cooling system fares particularly well due to the small vertical temperature difference and low airflow velocities.

\subsection{Ventilation effectiveness}

The ventilation effectiveness was assessed with the overall ventilation effectiveness as well as the ventilation effectiveness in the occupied zone.

For the calculation in the occupied zone, the values at points T3, T4, T6 and T7 were used as basis. Individual gas content in the air is usually given in ppm with respect to the volume fraction of the substance in the air. Consequently, the calculated mass field of $\mathrm{CO}_{2}$ was converted into this unit.

Table 6. Concentration values.

\begin{tabular}{|c|c|c|c|c|}
\hline Symbol* & Unit & $\begin{array}{c}\text { Ceiling } \\
\text { cooling }\end{array}$ & $\begin{array}{c}\text { Fan coil } \\
\text { unit }\end{array}$ & $\begin{array}{c}\text { Flat wall } \\
\text { inlet }\end{array}$ \\
\hline $\mathrm{c}_{\mathrm{s}}$ & $\mathrm{ppm}$ & 301 & 301 & 301 \\
\hline $\mathrm{c}_{\mathrm{e}}$ & $\mathrm{ppm}$ & 609 & 332 & 325 \\
\hline$\langle\mathrm{c}\rangle$ & $\mathrm{ppm}$ & 603 & 338 & 313 \\
\hline $\mathrm{c}_{\mathrm{oz}}$ & $\mathrm{ppm}$ & 660 & 336 & 302 \\
\hline$\langle\mathrm{CRE}\rangle$ & $/$ & 1.02 & 0.83 & 1.92 \\
\hline $\mathrm{CRE}_{\mathrm{oz}}$ & $/$ & 0.86 & 0.88 & 1.53 \\
\hline
\end{tabular}

$* c_{\mathrm{s}}-$ supply air $\mathrm{CO}_{2}$ concentration; $\mathrm{c}_{\mathrm{e}}-$ exhaust air $\mathrm{CO}_{2}$ concentration; $\mathrm{c}_{\mathrm{oz}}-\mathrm{CO}_{2}$ concentration in the occupied zone; $\mathrm{CRE}_{\mathrm{oz}}-$ contaminant removal effectiveness in the occupied zone

The concentration field, which served as a basis for assessing the ventilation effectiveness, is shown in Fig. 4 (column 4). In all cases, a higher $\mathrm{CO}_{2}$ concentration in the vicinity of humans or more precisely in the vicinity

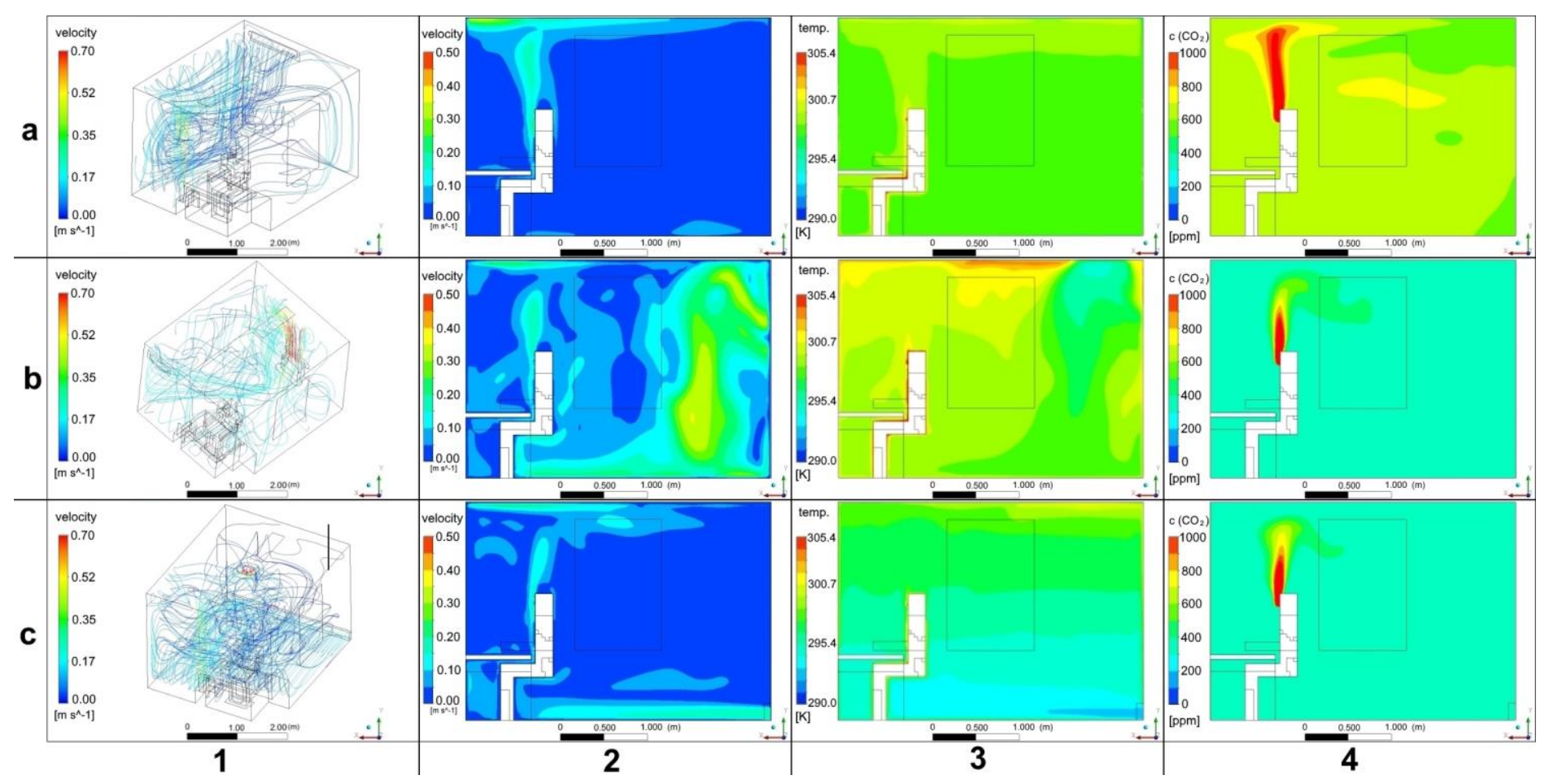

Fig. 4. Velocity pathlines (column 1), velocity (2), temperature (3) and concentration fields (4) in XY cross-section for (row a) chilled ceiling cooling, (b) fan coil unit and (c) cooling with flat wall displacement inlets 
of the nasal aperture can be observed. Generally, the $\mathrm{CO}_{2}$ concentration is below $800 \mathrm{ppm}$, which is not harmful for human health.

Table 6 shows the concentration values and the ventilation effectiveness for all three AC system combinations. The highest ventilation effectiveness is achieved with the flat wall inlets. This is due to the way the air is distributed into the lower part of the room from where it displaces the older room air.

It should be noted that high contaminant removal effectiveness means high air quality, but also a higher energy consumption. If the systems only performed the task of ventilation, the air flow could be greatly reduced without the risk of achieving unsatisfactory contaminant removal effectiveness.

\subsection{Combined thermal comfort and ventilation effectiveness assessment}

Combined indoor environment assessment was determined based on the simulated thermal comfort and ventilation effectiveness. Average space PMV value and overall ventilation effectiveness were used in the calculation. Since we assessed an office environment, the selected thermal comfort weights values were 0.5 , 0.6 and 0.7. Simulation results are presented in table 7 .

Table 7. Indoor environment indicator calculation results.

\begin{tabular}{|c|c|c|c|c|c|c|c|}
\hline \multicolumn{2}{|r|}{ Symbol } & \multicolumn{2}{|c|}{$\begin{array}{l}\text { Ceiling } \\
\text { cooling }\end{array}$} & \multicolumn{2}{|c|}{$\begin{array}{c}\text { Fan coil } \\
\text { unit }\end{array}$} & \multicolumn{2}{|c|}{$\begin{array}{c}\text { Flat wall } \\
\text { inlets }\end{array}$} \\
\hline & PMV & \multicolumn{2}{|c|}{$\mathrm{B}$} & \multicolumn{2}{|c|}{$\mathrm{C}$} & \multicolumn{2}{|c|}{$\mathrm{B}$} \\
\hline & $\mathrm{X}$ & \multicolumn{2}{|c|}{2} & \multicolumn{2}{|c|}{3} & \multicolumn{2}{|c|}{2} \\
\hline \multicolumn{2}{|r|}{ CRE } & \multicolumn{2}{|c|}{1.02} & \multicolumn{2}{|c|}{0.83} & \multicolumn{2}{|c|}{1.92} \\
\hline \multicolumn{2}{|r|}{$\mathrm{Y}$} & \multicolumn{2}{|c|}{1} & \multicolumn{2}{|c|}{2} & \multicolumn{2}{|c|}{1} \\
\hline \multirow{3}{*}{ IIEQ } & $\mathrm{W}_{\mathrm{IEQ}}=0.5$ & 1.5 & $\mathrm{~A}$ & 2.0 & $\mathrm{~B}$ & 1.5 & $\mathrm{~A}$ \\
\hline & $\mathrm{W}_{\mathrm{IEQ}}=0.6$ & 1.6 & A & 2.2 & B & 1.6 & $\mathrm{~A}$ \\
\hline & $\mathrm{W}_{\mathrm{IEQ}}=0.7$ & 1.7 & $\mathrm{~B}$ & 2.4 & $\mathrm{C}$ & 1.7 & $\mathrm{~B}$ \\
\hline
\end{tabular}

For all thermal comfort weights, ceiling cooling and wall outlets achieve the best results as both systems achieved the same thermal comfort and ventilation effectiveness categories: for $\mathrm{W}_{\mathrm{IEQ}}=0.5$ and 0.6 the systems achieve category $\mathrm{A}$, whereas for $\mathrm{W}_{\mathrm{IEQ}}=0.7$ category B is achieved. A similar trend was noted for the fan coil unit which in comparison achieves lower categories.

The results thus indicate that for the calculation of the indoor environment indicator, the appropriate thermal comfort weight value is of great importance as it significantly effects the overall result and achieved indoor environment category.

\section{Discussion and conclusions}

A multi-criteria designing approach of indoor environment is crucial, since low-quality indoor environment can have negative consequences both from the stand point of energy use as well as for the health of the building users. The presented numerical study compares three cooling and ventilation systems combinations and their impact on the indoor environment quality.

Chilled ceiling cooling in combination with displacement ventilation has proven to be very favourable from the point of view of thermal comfort, as it achieved high results, both according to the whole body thermal comfort $(\mathrm{PMV}=0.23)$ and according to the local discomfort indices. The advantages of this system are the low air flow velocity, comfortable operative temperature and, in combination with displacement ventilation, high ventilation efficiency $(\langle\mathrm{CRE}\rangle=1.02)$. It does however achieve slightly unfavourable results with regard to the contaminant removal effectiveness in the occupied zone in comparison to the other two systems, which is due to the fact that the fresh supply air flow is reduced to a minimum.

In the case of the fan coil unit, the PMV $=0.73$ indicates that the system is somewhat less comfortable in comparison to ceiling cooling and wall outlets. The disadvantages of fan coil cooling are reflected in higher local air velocities $(\langle\mathrm{v}\rangle=0.103 \mathrm{~m} / \mathrm{s})$, which can cause a draught sensation. In addition, a fairly high surface temperature of the surrounding walls and human body model was achieved, which results in a lower level of comfort. From the ventilation effectiveness standpoint the system achieved the lowest results $(\langle\mathrm{CRE}\rangle=0.83)$.

The flat wall inlets system achieved a solid result from the stand point of whole body thermal comfort $(\mathrm{PMV}=-0.26)$ as well as high ventilation effectiveness $(\mathrm{CRE}=1.92)$. High ventilation effectiveness is achieved mainly due to the supply of high fresh air flow rates, which is also associated with higher energy consumption for ventilation. The system fares comparably to ceiling cooling in terms of whole body thermal comfort and favourably in terms of ventilation effectiveness. As a result of higher airflow velocities and thermal stratification, the system fares less favourably in terms of local discomfort although highest possible categories are achieved for all the local discomfort indices.

The comparison of indicators shows that the ceiling cooling and wall openings achieve the same internal environmental quality, which is expected, since both systems have reached the same categories from the point of view of thermal comfort and ventilation effectiveness. Nevertheless, it should be pointed out that the indicators of local discomfort are not taken into account in the evaluation of the indoor environment quality $I_{I E Q}$, where ceiling cooling turns out to be slightly less discomfortable. The fan coil unit reaches lower categories compared to the other systems and therefore has an overall worse internal environment quality.

The presented study indicates the importance of multi-criteria designing of indoor environment. The presented indicator for indoor environment quality $I_{I E Q}$ offers an integral evaluation of the indoor environment through a simple calculation. In the future a number of improvements to the indicator can be made, which would help to achieve a more precise characterization of the indoor environment quality with a joint indicator. First, it is necessary to appropriately determine the $\mathrm{W}_{\text {IEQ }}$ 
weights (dependant on the investigated space's purpose). Attention should also be given to the determination of appropriate ventilation effectiveness intervals, which define the parameter categories.

\section{References}

[1] G. Krese, J. Mandelj, M. Prek, V. Butala, Energy Efficiency Assessment of Existing Buildings Based on Measurements of HVAC Systems Electric Energy Consumption: A Case Study, Proc. Clima 2013 - 11th REHVA World Congr. 8th Int. Conf. IAQVEC. (2013) 8.

http://www.iservcmb.info/sites/default/files/resul ts/Publications-and-other-

dissemination/Papers/D9.15.1.6_Paper_CaseStudy_CLIMA-2013_Jun-2013_UL.pdf.

[2] N.E. Klepeis, W.C. Nelson, W.R. Ott, J.P. Robinson, A.M. Tsang, P. Switzer, J. V. Behar, S.C. Hern, W.H. Engelmann, The National Human Activity Pattern Survey (NHAPS): A resource for assessing exposure to environmental pollutants, J. Expo. Anal. Environ. Epidemiol. 11 (2001) 231-252. doi:10.1038/sj.jea.7500165.

[3] E. Mundt, H.M. Marhisen, P. V. Nielsen, A. Moser, eds., Ventilation Effectiveness, REHVA, Federation on European Heating and Airconditioning Associations, 2004. doi:10.1080/14733315.2004.11683922.

[4] R. Tomasi, M. Krajčík, A. Simone, B.W. Olesen, Experimental evaluation of air distribution in mechanically ventilated residential rooms: Thermal comfort and ventilation effectiveness, Energy Build. 60 (2013) 28-37. doi:10.1016/j.enbuild.2013.01.003.

[5] L. Schellen, M.G.L.C. Loomans, M.H. De Wit, B.W. Olesen, W.D.V.M. Lichtenbelt, Effects of different cooling principles on thermal sensation and physiological responses, Energy Build. 62 (2013) 116-125. doi:10.1016/j.enbuild.2013.01.007.

[6] P.O. Fanger, Thermal comfort: Analysis and applications in environmental engineering, 1970.

[7] G. Gan, Evaluation of room air distribution systems using computational fluid dynamics, Energy Build. 23 (1995) 83-93. doi:10.1016/0378-7788(95)00931-0.

[8] ANSYS Fluent, ANSYS FLUENT Theory Guide, Release 18.2. (2017). doi:10.1016/01403664(87)90311-2.

[9] Q. Chen, Comparison of different k- $\varepsilon$ models for indoor air flow computation, Int. J. Comput. Methodol. 28 (1995) 353-369. doi:10.1080/10407799508928838.

[10] O. Rouaud, M. Havet, Computation of the airflow in a pilot scale clean room using K- $\varepsilon$ turbulence models, Int. J. Refrig. 25 (2002) 351361. doi:10.1016/S0140-7007(01)00014-7.

[11] A.J. Gadgil, C. Lobscheid, M.O. Abadie, E.U.
Finlayson, Indoor pollutant mixing time in an isothermal closed room: An investigation using CFD, Atmos. Environ. 37 (2003) 5577-5586. doi:10.1016/j.atmosenv.2003.09.032.

[12] J. Srebric, V. Vukovic, G. He, X. Yang, CFD boundary conditions for contaminant dispersion, heat transfer and airflow simulations around human occupants in indoor environments, Build. Environ. 43 (2008) 294-303. doi:10.1016/j.buildenv.2006.03.023.

[13] ISO, ISO 7730: Ergonomics of the thermal environment Analytical determination and interpretation of thermal comfort using calculation of the PMV and PPD indices and local thermal comfort criteria, Management. 3 (2005) 605-615. doi:10.1016/j.soildyn.2004.11.005.

[14] Ansi/Ashrae, ANSI/ASHRAE 55:2004 Thermal Environmental Conditions for Human Occupancy, Ashrae. 2004 (2004) 30. doi:10.1007/s11926-011-0203-9.

[15] I. Standard, Iso_7730_2005, 2005 (2005).

[16] H. Rietschel, H. Esdorn, Raumklimatechnik: Band 1: Grundlagen, VDI, 1994.

[17] Verband deutscher Ingenieure, Berechnung der thermischen Lasten und Raumtemperaturen (Auslegung Kühllast und Jahressimulation) VDI 2078, Beuth Verlag, Berlin, 2015.

[18] J. Laustsen, Energy Efficiency Requirements in Building Codes, Energy Efficiency Policies for New Buildings, International Energy Agency (IEA), Paris, 2008. doi:10.1.1.378.1012.

[19] Krantz, Wandquellauslässe Q-W, (n.d.). https://cdn.caverion.com/docs/defaultsource/krantz-docs/krantz-produkte/d1-4-5_q-w_wandquellauslass_05-2010$\overline{1}$ kr.pdf?sfvrsn=1 $\bar{b} 36 \mathrm{e} 7 \mathrm{a} \_2$ (accessed July 12, 2018).

[20] TROX, Ceiling swirl diffusers, (2017). https://www.trox.de/en/downloads/c1eb60c3f46 814c7/00261701_0.pdf?type=product_info (accessed July 12, 2018).

[21] Hidria, Hidria - Fan Coils - Climmy E, (n.d.). http://www.hidria.com/Static/upload/file/Katalog Climmy E.PDF (accessed July 12, 2018).

[22] Krantz, Wand-Luftdurchlässe, (n.d.). https://cdn.caverion.com/docs/defaultsource/krantz-docs/krantz-downloads/krantzprodukte-broschüren/d1-2-0_k188_wandluftdurchlässe_2005-1-kr.pdf?sfvrsn=cf0bbf7b_8 (accessed July 12, 2018).

[23] Krantz, Drallauslass DD-N für Deckeneinbau, (n.d.). https://cdn.caverion.com/docs/defaultsource/krantz-docs/krantz-produkte/d1-1-1_ddn_drallauslass_06$2014 \_$kr.pdf? $\overline{s f v}$ rsn $=$ ebda6e7a_2 (accessed July 12, 2018). 